\title{
Why Inference to the Best Explanation Doesn't Secure Empirical Grounds for Mathematical Platonism
}

by Kenneth Boyce

Abstract: Proponents of the explanatory indispensability argument for mathematical platonism maintain that claims about mathematical entities play an essential explanatory role in some of our best scientific explanations. They infer that the existence of mathematical entities is supported by way of inference to the best explanation from empirical phenomena and therefore that there are the same sort of empirical grounds for believing in mathematical entities as there are for believing in concrete unobservables such as quarks. I object that this inference depends on a false view of how abductive considerations mediate the transfer of empirical support. More specifically, I argue that even if inference to the best explanation is cogent, and claims about mathematical entities play an essential explanatory role in some of our best scientific explanations, it doesn't follow that the empirical phenomena that license those explanations also provide empirical support for the claim that mathematical entities exist.

\section{Introduction}

Proponents of indispensability arguments for mathematical platonism contend that claims about mathematical entities are indispensable to some of our best scientific theories or explanations in just the same way as claims about concrete unobservables such as quarks. ${ }^{1}$ From this they typically draw two conclusions: First, there are the same sort of empirical grounds for believing that mathematical entities exist as there are for believing that the concrete unobservables postulated by our best scientific theories and explanations exist. Second, because that is the case,

\footnotetext{
${ }^{1}$ For a general overview of such arguments see (Colyvan 2015).
} 
those who would affirm the existence of such concrete unobservables, but deny the existence of mathematical entities, are caught up in a kind of epistemic inconsistency.

The classic Quine-Putnam indispensability argument attempts to establish these conclusions by emphasizing the alleged fact that quantification over mathematical entities is required for the purpose of adequately formulating some of our best scientific theories. Because this is the case, the argument would have it, those theories are true only if mathematical entities exist. The argument further relies on a doctrine of confirmational holism, according to which the empirical evidence that supports our best theories confirms them in their totality rather than differentially confirming some parts but not others. ${ }^{2}$ As will be explored in more detail below, however, the doctrine of confirmational holism is subject to numerous objections, and for that reason the Quine-Putnam indispensability argument's reliance on it has often been taken to be a significant liability. ${ }^{3}$

The more recent explanatory indispensability argument seeks to overcome this liability by emphasizing the alleged fact that claims about mathematical entities play an essential explanatory role in some of our best scientific explanations. In so doing, this version attempts to show that the existence of mathematical entities is confirmed by way of inference to the best explanation from empirical phenomena. ${ }^{4}$ I argue, however, that this explanatory indispensability argument fails to overcome the deficiencies of its predecessor. More specifically, I argue that it relies on a false view of how abductive inferences mediate the transfer of evidential support. I show that even if inference to the best explanation is cogent, and claims about mathematical

\footnotetext{
${ }^{2}$ See (Quine 1981a; 1981b; 1948; 1951) and (Putnam 1971; 1975) for classical sources of inspiration for this argument. See (Liggins 2008), however, for a challenge to the claim that either Quine or Putnam actually advocated the argument that has come to bear their name.

${ }^{3}$ For some discussions of this liability, see (Busch 2011; 2012), (Leng 2010), (Maddy 1992; 1995; 1997), (Morrison 2010; 2012), (Peressini 2008), (Sober 1993), and (Vineberg 1996).

${ }^{4}$ Baker $(2005 ; 2009 ; 2016)$ and Colyvan $(1999 ; 2001 ; 2002 ; 2006 ; 2010 ; 2012)$ provide the most influential articulations of this argument.
} 
entities sometimes play an essential and ontologically significant explanatory role in some of our best scientific explanations, it doesn't follow that the empirical phenomena that license those explanations also provide empirical support for the existence of mathematical entities.

\section{The Prima Facie Case Against Empirical Confirmation}

As indicated above the explanatory indispensability argument is motivated in part as an attempt to overcome some of the deficiencies of its predecessor, the Quine-Putnam indispensability argument. The latter has been subject to numerous objections. Some have objected, for example, to the claim that quantification over mathematical entities is in fact required in order to adequately formulate our best scientific theories. ${ }^{5}$ Others have rejected Quine's criterion of ontological commitment and along with it the premise that our best scientific theories are true only if mathematical entities exist. ${ }^{6}$ But even if these premises are granted, the argument's reliance on a simplistic doctrine of confirmational holism has also been seen as problematic.

A common objection, for instance, is that the widespread use of idealization within science shows that not all components of scientific theories purport to represent the world exactly as is. So it is naïve to think that the evidence supporting those theories recommends believing all of their components. ${ }^{7}$ In the context of the indispensability argument, furthermore, this concern is exacerbated by the fact that some philosophers maintain that mathematical portions of scientific theories in particular are among those not aimed at representing the world directly, but serve rather to do things like enhance the expressive power of our theories, or to facilitate the making of certain inferences. ${ }^{8}$

\footnotetext{
${ }^{5}$ See (Field 1980) for an influential challenge to this claim.

${ }^{6}$ See for example (Azzouni 2004; 2012), (Melia 1995; 2000), and (Yablo 2005).

${ }^{7}$ See (Batterman 2002), (Leng 2010) and (Maddy 1992; 1995; 1997: 143-154).

${ }^{8}$ See (Melia 2000; 2002; 2008), (Saatsi 2011), and (Yablo 2005).
} 
Another issue is that this version of confirmational holism seems to commit its proponents to an overly naïve form of scientific realism. As Jacob Busch (2011:144-145) has noted, those who embrace such a strong doctrine of confirmational holism prevent themselves from endorsing a "separation strategy" for responding to the pessimistic meta-induction, a strategy that involves distinguishing between different components of our best scientific theories and maintaining that only some of them are well confirmed. ${ }^{9}$ Contrary to what the doctrine of confirmational holism on which the Quine-Putnam indispensability argument relies would recommend, many contemporary scientific realists are not wholesale realists but selective ones. ${ }^{10}$

Finally, even setting the above concerns aside, the claim that the empirical evidence supporting our best scientific theories also supports each of their implications is formally suspect. As Elliott Sober (2011: 187-189) points out, that claim is reminiscent of Carl G. Hempel's (1945: 103) “special consequence condition" on confirmation, which states that whatever evidence confirms a statement also confirms each of its implications. And this principle, Sober observes, is known to be subject to counterexamples. The fact, for example, that a fair coin recently flipped ten times came up heads on the first flip provides some meager evidence for the hypothesis that it came up heads all ten times (at least in the sense that it renders that hypothesis more probable). Since the hypothesis predicts this fact, it is (at least to some extent) confirmed by it. But that same fact provides no evidence whatsoever for that hypothesis' implication that the second coin toss came up heads. Since the outcomes of each coin toss are probabilistically independent of one another, that implication fails to have any bearing at all on

\footnotetext{
${ }^{9}$ For a similar point see (Morrison 2012: 265-266).

${ }^{10}$ See (Chakravartty 2017) and (Psillos and Ruttkamp-Bloem 2017) for some recent overviews of selective scientific realism.
} 
our expectations concerning the outcome of the first toss. And because it fails to predict that outcome, it also fails to be confirmed by it.

Unfortunately for defenders of the Quine-Putnam indispensability argument, furthermore, their opponents have argued that something similar occurs with respect to the pure mathematical implications of our best scientific theories. Many have argued, for example, that because mathematical entities are both non-spatiotemporal and causally inert if they exist, pure mathematical claims do not by themselves generate any empirical predictions and so are not themselves confirmed by the empirical data that confirms the scientific theories implying them. ${ }^{11}$ A related position is that the pure mathematical portions of our best theories are not (or at least not typically) among those that are empirically tested so as to be subject to potential disconfirmation, and thereby also not among those which are confirmed by those tests. ${ }^{12}$

In fact, given how commonly these last two considerations are raised in the literature, and how compelling many philosophers find them, we may say that together they constitute a positive prima facie case for the conclusion that the existence of mathematical entities is not empirically confirmed. At the very least, these considerations seem to offer anti-platonist scientific realists principled grounds for believing that our empirical evidence bears on the question of whether concrete unobservables such as quarks exist in a different way than it bears on the question of whether mathematical entities exist. Thus any contemporary version of the indispensability argument that would attempt to lay on such scientific realists a charge of epistemic inconsistency needs to address this prima facie case.

\section{The Explanatory Indispensability Argument}

${ }^{11}$ See for instance (Balaguer 1998: 132-136; 2009), (Leng 2005b; 2010), and (Vineberg 1996).

${ }^{12}$ See (Busch 2012), (Maddy 1992; 1995; 1997: 138-143), (Parsons 1983: 195-197), and (Sober 1993; 2011: 200-211). 
The explanatory indispensability argument addresses this case by emphasizing the explanatory role mathematics plays in science. As with scientific theories and hypotheses more generally, one might hold, not every component of a given scientific explanation needs to be true in order for that explanation to be good. A standard explanation of Brownian motion, for instance, might make the simplifying assumption that collisions between molecules are perfectly elastic. But it does not fail to be a good explanation for that reason. It does fail to be a good explanation, however, should it turn out that molecules don't exist. We might say the claim that molecules exist plays an essential explanatory role in this explanation, in the sense that this account of Brownian motion fails as an explanation should that claim turn out to be false. ${ }^{13}$ Proponents of the explanatory indispensability argument for mathematical platonism contend that claims about mathematical entities sometimes also play an essential explanatory role in some of our best scientific explanations of empirical phenomena in just this sense. ${ }^{14}$

Alan Baker $(2005 ; 2009,2016)$ argues, for example, that theorems from number theory play an essential explanatory role in our best scientific explanation of the prime-numbered year lifecycles of certain subspecies of periodical cicada. The reason these cicadas have primenumbered year lifecycles, it is hypothesized, is because in their evolutionary past it was advantageous for their ancestors to have lifecycles that minimized intersection with those of other periodical organisms. Lifecycles that do this are those whose number of years maximize least common multiples with other natural numbers. It can be demonstrated using number theory, furthermore, that the natural numbers which have this feature are prime numbers. Since

${ }^{13}$ For a historically and philosophically informative discussion of the role that Brownian motion played in convincing the scientific community of the reality of atoms see (Maddy 1997: 133-157).

${ }^{14}$ See (Colyvan 2001:76-86) for an argument that the sense in which mathematics may be regarded as "indispensable" to our best scientific theories is best understood in terms of its contributions to those theories' explanatory virtues. 
it seems that this explanation is no good unless the number-theoretic claims to which it appeals are true, Baker concludes it is one in which claims about mathematical entities play an essential explanatory role. ${ }^{15}$ Because claims about mathematical entities play such a role in some of our best scientific explanations, Baker also concludes, we ought to believe that mathematical entities exist.

One can easily see how the explanatory indispensability argument (or "EIA") promises to improve on the Quine-Putnam indispensability argument. While perhaps not all components of our best scientific theories are aimed at directly representing the world as is, scientific realists are arguably committed to thinking that the explanatorily essential components of our best theories and explanations are so aimed. And while perhaps not all quantification that occurs in the formulation of our best scientific theories and explanations needs to be taken with ontological seriousness, scientific realists are arguably committed to taking quantification that occurs in the formulation of claims playing an essential explanatory role in those theories and explanations in that way. It is by virtue of these commitments, one might think, for example, that scientific realists have principled grounds for insisting that our acceptance of the explanation of Brownian motion mentioned above requires us to believe in molecules, in spite of the fact that it does not also require us to believe that collisions between molecules are perfectly elastic.

Insofar as scientific realists are committed to the cogency of inference to the best explanation, furthermore, they are also committed to there being a link between confirmation and explanatory contribution. Indeed it is by virtue of this commitment, one might think, that scientific realists take themselves to have empirical grounds for believing in the various concrete unobservables postulated by our best scientific theories, in spite of the lack of a general

\footnotetext{
${ }^{15}$ Or in Baker's (2009: 613) own wording, it is an example of a case in which "mathematical objects play an indispensable explanatory role in science."
} 
guarantee that the empirical evidence that favors those theories favors each of their implications.

Scientific realists can hold that certain claims about unobservables play an essential role in accounting for empirical phenomena, thereby securing, by way of inference to the best explanation, that there is empirical support for those claims. Proponents of EIA would further add that we have empirical grounds for believing in mathematical entities for precisely the same reason.

While EIA is initially promising for all of the above reasons, however, it too ultimately fails to overcome the prima facie case described in the previous section for the conclusion that the existence of mathematical entities receives no empirical support. And so it too fails to convict scientific realists who are anti-platonists of epistemic inconsistency. Or so I will argue in the remaining sections.

\section{The Explanatory Argument for Empirical Grounds}

While EIA is meant to serve as a leveraging argument aimed at convincing those not already on board to adopt a mathematical ontology, its conclusion that there are empirical grounds for believing that mathematical entities exist also has important implications for mathematical epistemology. In order to better focus on the latter, consider for example, not how mathematical nominalists might respond to EIA, but those who I will call "mathematical rationalists." Mathematical rationalists (as I am characterizing them) are mathematical platonists who deny that we have empirical evidence for believing that mathematical entities exist. Rather, they maintain, our grounds for believing in mathematical entities are entirely a priori. ${ }^{16}$

\footnotetext{
${ }^{16}$ Frege (1884), at least by some interpretations, serves as a historically prominent example of someone who held this view. Bengson (2015), Hale and Wright (2001; 2002), and Marcus (2015) serve as contemporary examples.
} 
Mathematical rationalists might also be scientific realists who accept the cogency of inference to the best explanation and agree that IBE from various empirical phenomena recommends believing hypotheses that require there to be mathematical entities. But they might also hold that IBE recommends believing such hypotheses only because we already have rationally sufficient a priori grounds for believing their pure mathematical implications. Had we no such grounds, they might maintain, then various other nominalistically acceptable alternative explanations would have been preferable. In this way mathematical rationalists might hold that IBE from empirical phenomena recommends belief in mathematical explanations without supplying empirical evidence for the claim that mathematical entities exist.

How might proponents of EIA who do take the role mathematics plays in scientific explanation to supply us with empirical grounds for believing that mathematical entities exist respond to such a view? Here it is worth emphasizing that proponents of EIA do not merely argue that IBE from empirical phenomena sometimes favors mathematically imbued hypotheses, but also that pure mathematical claims play an essential explanatory role within some of those hypotheses. So one response proponents of EIA might give is to argue that because of the way in which mathematical claims contribute to the goodness of our best explanations, they themselves are favored by IBE, in a manner that supplies us with additional reasons to believe them. ${ }^{17}$

It is this consideration that supplies us with what I will call "the explanatory argument for empirical grounds." According to this argument, when IBE from empirical phenomena licenses the acceptance of a certain hypothesis, the empirical evidence supplied by that phenomena serves as evidence for each of the explanatorily essential components of that hypothesis. And since (the

\footnotetext{
${ }^{17}$ See for example (Baker 2016: 334) and (Colyvan 2006: 227-228, 234-235) for suggestions along these lines.
} 
argument goes) claims about mathematical entities sometimes play an essential explanatory role in our best scientific explanations, it follows that there is empirical evidence that mathematical entities exist.

Note that this explanatory argument for empirical grounds presupposes the correctness of an analog of Hempel's special consequence condition, albeit one that is sensitive to the kind of explanatory role played by the implications of the hypothesis in question. More precisely, it presupposes the following principle:

(Explanatory Consequence) If $\mathrm{H}$ is the best explanation of $\mathrm{E}$ (so that $\mathrm{E}$ licenses the acceptance of $\mathrm{H}$ via inference to the best explanation) and $\mathrm{C}$ plays an essential explanatory role in the explanation that $\mathrm{H}$ provides for $\mathrm{E}$, then $\mathrm{E}$ provides evidence for $\mathrm{C}$. Opponents of the explanatory argument for empirical grounds might object that this principle is suspect by association. But for reasons to which I have already alluded, Explanatory Consequence is initially more plausible than the special consequence condition. As previously noted, the special consequence condition is subject to counterexamples because there are cases in which a hypothesis predicts certain observations (and so winds up confirmed by them) but has implications which do not predict those same observations (and so are not confirmed by them). But it is not immediately obvious that Explanatory Consequence will be subject to any counterexamples of that sort. The conditions in its antecedent will be fulfilled only if the relevant claims play an essential role in accounting for the evidence. Since the claim that molecules exist plays an essential role in our best explanations of Brownian motion, for example, it does seem to follow that the phenomenon of Brownian motion affords us with empirical evidence for that claim. 
In fact, given that believers in the cogency of IBE are committed to there being a tight connection between explanation and evidential support, it is tempting to think they are thereby committed to Explanatory Consequence. If there could be cases in which some claim plays an essential explanatory role in accounting for some phenomena and yet receives no evidential support from the fact that phenomena occurs, then this might seem to break the link between explanation and confirmation in a manner that is unacceptable to proponents of IBE. ${ }^{18}$ While this is a tempting thought, however, it is also mistaken. Even if IBE is cogent, Explanatory Consequence is subject to counterexamples, and because it is, the explanatory argument for empirical grounds fails. I develop such a counterexample in the next section and then go on to discuss further how the existence of such counterexamples bears on the success of EIA.

\section{A Counterexample to Explanatory Consequence}

My counterexample makes use of the following scenario:

(Heart Defect) There is a population in which a common genetic defect predisposes people toward suffering from heart attack under certain conditions. The defect is such that, for those who have it, frequent exercise causally contributes to the weakening of the heart. Thus engaging in frequent exercise often causes those who have the defect to suffer from heart attack. The diet of this population is also such, however, that those who fail to engage in frequent exercise are virtually guaranteed to suffer from heart attack on account of high cholesterol levels. Within this population, furthermore, the only two causes of heart attack are the weakening of the heart due to frequent exercise among those who have the genetic defect and high cholesterol levels. These two causes never occur together. A given member of this population, Hardy, has had a heart attack. We

\footnotetext{
${ }^{18} \mathrm{An}$ argument along these lines from the cogency of IBE to a principle like Explanatory Consequence is discussed by Morrison (2012: 274-275).
} 
have no specific, relevant information about Hardy himself, other than that he is a member of this population. We do have available to us, however, data regarding the prevalence of the genetic defect, the proportion of those who regularly exercise, and the frequency of causes of heart attack among members of this population.

Let 'A' stand for the observed fact that Hardy has had a heart attack. Let ' $W$ ' stand for the hypothesis that Hardy has the genetic defect described above and has had a heart attack on account of the weakening of the heart caused by frequent exercise. And let ' $F$ ' stand for the claim that Hardy has engaged in frequent exercise. As I will soon demonstrate, it is possible that the following conditions hold: (1) We may properly infer W from A via inference to the best explanation, (2) F plays an essential explanatory role in the explanation that $\mathrm{W}$ provides for $\mathrm{A}$, but (3) A provides no evidence for F. If it is indeed possible that all three of these conditions hold, we have a counterexample to Explanatory Consequence.

Here is an intuitive description of how this might happen: By far the most common cause of heart attack in this population is the weakening of the heart on account of frequent exercise. So (given our background information) IBE licenses the conclusion that Hardy's heart attack was caused in this manner. So the first condition is met. Since the claim that Hardy engaged in frequent exercise is essential to this causal explanation of his heart attack, the second condition is also met (the proposed explanation is no good as an explanation should the claim that Hardy exercised turn out to be false). Nevertheless, if one is a member of this population, engaging in frequent exercise lowers the probability that one will suffer heart attack, by way of reducing one's risk from high cholesterol. Consequently, the fact that Hardy suffered from a heart attack lowers the probability of, and thereby counts as evidence against, the claim he engaged in frequent exercise. So the third condition is met. 
Lest one be in doubt as to the coherence of this intuitive description, here is some hypothetical population data that illustrates its possibility (see also Figure 1 below): The population contains a total of 100,000 people. 81,000 people in the population have the genetic defect. All of those 81,000 people suffer from heart attack. 80,000 of these 81,000 suffer from heart attack due to the weakening of the heart caused by frequent exercise. The remaining 1000 of these 81,000 do not engage in frequent exercise and suffer from heart attack on account of high cholesterol levels. The remaining 19,000 members of the population do not suffer from the genetic defect. Of those remaining 19,000, 17,000 of them engage in frequent exercise. Of those 17,000 , only 1000 suffer from heart attack due to high cholesterol. The other 2,000 of these 19,000 fail to engage in frequent exercise. All of them suffer from heart attack as a result of high cholesterol.

Fig. 1 Hypothetical Population Data for the Heart Defect Scenario ${ }^{19}$

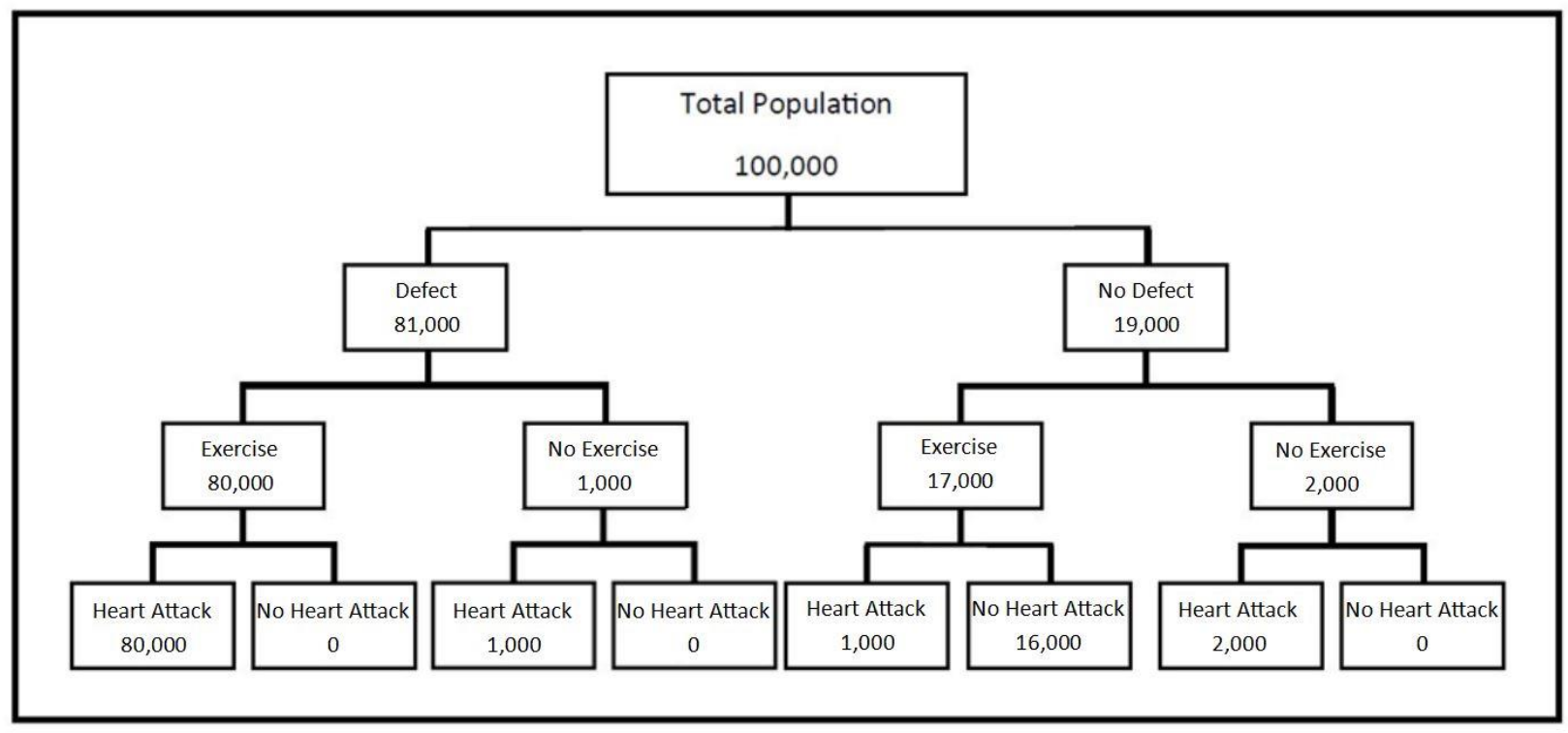

This population data, along with the assumption that our background information contains no relevant information about Hardy other than that he is a member of this population,

\footnotetext{
19 Thanks to Sarah Boyce for creating this diagram.
} 
delivers the following initial probabilities: $\mathrm{P}(\mathrm{W})=80 \%, \mathrm{P}(\mathrm{WIA}) \approx 95.2 \%, \mathrm{P}(\mathrm{F})=97 \%, \mathrm{P}(\mathrm{F} \mid \mathrm{A}) \approx$ 96.4\%. Note that while A substantially raises the probability of $\mathrm{W}$ in this case, A actually lowers the probability of F! Thus while A renders $\mathrm{W}$ highly probable, A fails to provide any additional reason whatsoever to believe $\mathrm{F}$ (in fact, it provides us with a reason to lower our confidence that $\mathrm{F}$ is true), in spite of the fact that $\mathrm{F}$ plays an essential explanatory role in the explanation that $\mathrm{W}$ provides for A. Thus we have a counterexample to Explanatory Consequence.

Since my purpose in this section is merely to provide a counterexample to a principle required by the explanatory argument for empirical grounds, it doesn't matter whether the case I have presented is analogous to the alleged examples of mathematical explanation in science provided by advocates of EIA. But it is worth noting that there arguably are crucial respects in which it is analogous. The hypothesis that Hardy has the defect and suffered a heart attack on account of frequent exercise entails that Hardy's having engaged in frequent exercise is explanatorily relevant to the occurrence of his heart attack. But the probability that Hardy would suffer a heart attack given that he engaged in frequent exercise is either less than (as in the example I gave above) or equal to (as a modified version of that example would secure) the prior probability that Hardy would suffer a heart attack. So, the assumption that Hardy engages in frequent exercise does not render the claim that Hardy suffers from a heart attack any more expectable than does the claim that Hardy does not engage in frequent exercise. Also, the initial grounds for accepting that Hardy engaged in frequent exercise in this example have to do with initial data about the population at large rather than an empirical test of that claim that opened it up to potential disconfirmation.

Similarly, as already noted, opponents of the indispensability argument have held that because mathematical entities are both non-spatiotemporal and acausal if they exist, the 
assumption that mathematical entities exist gives us no more reason to expect certain empirical phenomena than the assumption they do not. What the heart-defect example opens up, furthermore, is the conceptual possibility that this might be true even if claims about mathematical entities are explanatorily relevant to the occurrence of various empirical phenomena. As was also previously noted, some opponents of the indispensability argument contend that the existence of mathematical entities is not empirically confirmed by the evidence that supports our best theories because the pure mathematical implications of those theories are not empirically tested in a way that opens them up to potential disconfirmation. The heart-defect example further shows that this might be so even if the examples of mathematical explanation within science claimed by proponents of EIA are genuine.

To put things another way, in Section 2 we saw that the above two considerations about the relationship between our empirical evidence and pure mathematical claims constitute a prima facie case for the conclusion that the existence of mathematical entities is not empirically confirmed. What the heart-defect example illustrates, furthermore, is that appealing to a principle like Explanatory Consequence is not sufficient to overturn that prima facie case even if claims about mathematical entities do play an essential explanatory role in some of our best scientific explanations. The heart-defect example illustrates rather that Explanatory Consequence is subject to counterexamples in situations in which the explanatory claims in question do not by themselves generate the expectation that the relevant empirical phenomena will occur and are not themselves subject to empirical testing. And these are just the conditions that lead opponents of the indispensability argument to deny that the existence of mathematical entities receives empirical support.

\section{An Explanatory Indispensability Argument Without Establishing Empirical Grounds?}


One thing the counterexample offered in the previous section does not show, however, is that it is possible for IBE to license the acceptance of a hypothesis without its also being rational for us to believe each of its explanatorily essential components. In the scenario described, the probability that Hardy engaged in frequent exercise was already made extremely high by our background knowledge, did not drop significantly when the evidence that Hardy suffered a heart attack came in, and remained at least as high or higher than the probability of the hypothesis recommended by IBE. Likewise, a proponent of EIA might contend, since claims about mathematical entities play an essential and ontologically significant explanatory role in some of our best scientific explanations, scientific realists who are committed to the cogency of IBE are also committed to the belief that mathematical entities exist (regardless of whether there are empirical grounds for that belief).

As Russell Marcus (2014: 3584) observes, however, without some way of guaranteeing that the empirical support for mathematical explanations used in science transfers over to their pure mathematical implications, opponents of the indispensability argument need not concede that IBE does in fact favor hypotheses according to which mathematical entities exist. From the perspective of scientific realists who endorse the prima facie case against there being empirical support for pure mathematical claims, such hypotheses involve postulating strange, nonspatiotemporal, causally inert entities for which there is no empirical evidence whatsoever. And it seems perfectly reasonable given that perspective simply to deny that IBE recommends believing those hypotheses.

Here it might seem that I am retracting what I suggested at the outset of the paper I was willing to grant, namely that IBE is cogent and that claims about mathematical entities sometimes do play an essential and ontologically significant explanatory role in some of our best 
scientific explanations. There are at least two reasons however why what I am saying here is consistent with these claims.

First, even if it is true that some of our best scientific explanations imply that mathematical entities exist, it doesn't follow from the most sophisticated accounts of inference to the best explanation that IBE recommends endorsing those explanations. That is because, in order to avoid the objection that an explanation might be the "best of a bad lot," these accounts deny that it is enough for IBE to recommend a hypothesis that it be the best available; rather, it must also be sufficiently good. ${ }^{20}$ Scientific realists who are antecedently inclined to reject platonism might plausibly deny that the mathematical explanations cited by proponents of EIA are in fact sufficiently good (even if they are the best available) on the grounds that some their key components lack adequate empirical support.

Second, and more importantly, it need not be the case that EIA is unsound in order for it to be dialectically ineffective. The issue is not merely whether proponents of EIA are correct to insist on the premise that IBE licenses the acceptance of explanations in which claims about mathematical entities play an essential and ontologically significant explanatory role, but also whether they manage to offer their opponents a non-question-begging reason to believe that premise. We ourselves might well be mathematical platonists, for instance, who think there are rationally sufficient a priori grounds for believing that mathematical entities exist, and who are for that reason willing to concede that IBE licenses the acceptance of explanations which require there to be mathematical entities. Even so, we should all agree that it would be dialectically inappropriate to insist that opponents of EIA adopt this premise for that reason. As Baker (2009: 613) points out, "the reason for the 'detour' through empirical science" on the part of proponents

\footnotetext{
${ }^{20}$ See (Lipton 2004: 63) and (McCain 2016: 160-161) for discussions of this requirement.
} 
of the indispensability argument is "to avoid begging the question against the mathematical nominalist," which requires that we don't "assume the literal truth of pure mathematical claims at the outset." Given that EIA fails to establish there are empirical grounds for believing that mathematical entities exist, it also fails to provide its opponents with a non-question begging reason to believe the pure mathematical implications of the scientific explanations to which it points (at least when those implications are to be understood as having ontological significance). ${ }^{21}$

\section{Works Cited}

Azzouni, Jody (2012) “Taking the Easy Road Out of Dodge” Mind, 121, pp. 951-965.

Azzouni, Jody (2004) Deflating Existential Consequence (NY: Oxford University Press).

Baker, Alan (2016) "Parsimony and Inference to the Best Mathematical Explanation" Synthese, 193, pp. 333-350.

Baker, Alan (2009) "Mathematical Explanation in Science" British Journal for the Philosophy of Science, 60, pp. 611-633.

Baker, Alan (2005) “Are there Genuine Mathematical Explanations of Physical Phenomena?” Mind, 114, pp. 223-238.

Balaguer (2009) "Fictionalism, Theft, and the Story of Mathematics" Philosophia Mathematica, 17, pp. 131-162.

Balaguer, Mark (1998) Platonism and Anti-Platonism in Mathematics (NY: Oxford University

${ }^{21}$ For helpful comments on previous drafts, I would like to thank Mark Balaguer, Sarah Boyce, Lindsay Brainard, Matt Duncan, Luke Kallberg, various anonymous referees, and the audience members of numerous venues in which I presented previous versions of this paper. I would also like to thank the University of Missouri Research Board and the University of Missouri Philosophy Department for the generous provision of a research leave that allowed me to focus on this project. 
Press).

Bangu, Sorin Ioan (2008) "Inference to the best explanation and mathematical realism" Synthese, 160, pp. 13-20.

Batterman, Robert W. (2002) The Devil in the Details: Asymptotic Reasoning in Explanation, Reduction, and Emergence (NY: Oxford University Press).

Bengson, John (2015) “Grasping the Third Realm” Oxford Studies in Epistemology Volume 5 edited by Tamar Szabo Gendler and John Hawthorne (NY: Oxford University Press), pp. $1-38$.

Busch, Jacob (2012) “Can the New Indispensability Argument be Saved from Euclidean Rescues”Synthese, 187, pp. 489-508.

Busch, Jacob (2011) "Is the Indispensability Argument Dispensable" Theoria, 77, pp. 139-158. Busch, Jacob and Morrison, Joe (2016) “Should Scientific Realists be Platonists?" Synthese, 193, pp. 435-449.

Colyvan, Mark (2015) “Indispensability Arguments in the Philosophy of Mathematics" in The Stanford Encyclopedia of Philosophy edited by Edward N. Zalta (https://plato.stanford.edu/entries/mathphil-indis/).

Colyvan, Mark (2012) "Road Work Ahead: Heavy Machinery on the Easy Road” Mind, 121, pp. 1031-1046.

Colyvan, Mark (2010) “There is No Easy Road to Nominalism” Mind, 119, pp. 285-306.

Colyvan, Mark (2007) "Mathematical Recreation Versus Mathematical Knowledge" in Mathematical Knowledge edited by Mary Leng, Alexander Paseau, and Michael Potter (NY: Oxford University Press), pp. 109-122.

Colyvan, Mark (2006) "Scientific Realism and Mathematical Nominalism: A Marriage Made in 
Hell" in Rationality and Reality: Conversations with Alan Musgrave edited by Colin Cheyne and John Worrall (Dordrecht: Springer), pp. 225-237.

Colyvan, Mark (2002) "Mathematics and Aesthetic Considerations in Science" Mind, 111, pp. 69-74.

Colyvan, Mark (2001) The Indispensability of Mathematics (NY: Oxford University Press). Colyvan, Mark (1999) “Confirmation and Indispensability” Philosophical Studies, 96, pp. 1-19.

Chakravartty, Anjan (2017) "Scientific Realism" in The Stanford Encyclopedia of Philosophy edited by Edward N. Zalta (https://plato.stanford.edu/entries/scientific-realism/).

Daly, Chris and Langford, Simon (2009) "Mathematical Explanation and Indispensability Arguments" The Philosophical Quarterly, 39, pp. 641-658.

Field, Hartry (1980) Science Without Numbers: A Defense of Nominalism (NJ: Princeton, Princeton University Press).

Frege, Gottlob (1884) The Foundations of Arithmetic: A Logico-Mathematical Enquiry into the Concept of Number translated by J.L. Austin, second revised edition (NY: Harper \& Brothers 1950).

Hale and Wright (2002) “Benacerraf's Dilemma Revisited” European Journal of Philosophy, 10, pp. 101-129.

Hale and Wright (2001) The Reason's Proper Study: Essays Towards a Neo-Fregean Philosophy of Mathematics (NY: Oxford University Press).

Hempel, Carl G. (1945) "Studies in the Logic of Confirmation (II.)” Mind, 54, pp. 97-121. Leng, Mary (2010) Mathematics and Reality (NY: Oxford University Press).

Leng, Mary (2005a) "Mathematical Explanation" in Mathematical Reasoning and Heuristics 
edited by C. Cellucci and D. Gillies (London: King's College Publications), pp. 167-189.

Leng, Mary (2005b) "Platonism and Anti-Platonism: Why Worry?" International Studies in the Philosophy of Science, 19, pp. 65-84.

Liggins, David (2008) “Quine, Putnam, and the 'Quine-Putnam' Indispensability Argument" Erkenntnis, 68, pp. 113-127.

Lipton, Peter (2004) Inference to the Best Explanation second edition (NY: Routledge).

Maddy, Penelope (1997) Naturalism in Mathematics (NY: Oxford University Press).

Maddy, Penelope (1995) "Naturalism and Ontology” Philosophia Mathematica, 3, pp. 248-270.

Maddy, Penelope (1992) "Indispensability and Practice” The Journal of Philosophy, 89, pp. 275289.

Marcus, Russell (2014) “The Holistic Presumptions of the Indispensability Argument” Synthese, 191, pp. 3575-3594.

Marcus, Russell (2015) Autonomy Platonism and the Indispensability Argument (NY: Lexington Books).

McCain, Kevin (2016) The Nature of Scientific Knowledge: An Explanatory Approach (Springer).

Melia, Joseph (2008) “A World of Concrete Particulars" in Oxford Studies in Metaphysics Vol. 4 edited by Dean W. Zimmerman (NY: Oxford University Press), pp. 99-124.

Melia, Joseph (2002) "Response to Colyvan” Mind, 111, pp. 75-79.

Melia, Joseph (2000) “Weaseling Away the Indispensability Argument” Mind, 109, pp. 455-479.

Melia, Joseph (1995) “On What There's Not” Analysis, 55, pp. 223-229.

Morrison, Joe (2012) “Evidential Holism and Indispensability Arguments" Erkenntnis, 76, pp. 263-278. 
Morrison, Joe (2010) “Just How Controversial is Evidential Holism?” Synthese, 173, pp. 335352.

Parsons, Charles (1983) “Quine on the Philosophy of Mathematics” in Mathematics in Philosophy (Ithaca, NY: Cornell University Press), pp. 176-205.

Psillos, Stathis and Ruttkamp-Bloem, Emma (2017) “Scientific Realism: Quo Vadis? Introduction: New Thinking About Scientific Realism” Synthese, 194, pp. 3187-3201.

Putnam, Hilary (1975) “What is Mathematical Truth" Historia Mathematica, 2, pp. 529-543. Reprinted in Mathematics, Matter and Method by Hilary Putnam (NY: Cambridge University Press, 1979), pp. 323-357.

Putnam, Hilary (1971) Philosophy of Logic (NY: Harper \& Row). Reprinted in Mathematics, Matter and Method by Hilary Putnam (NY: Cambridge University Press, 1979), pp. 6078.

Quine, W.V. (1981a) "Success and Limits of Mathematization” in Theories and Things (Cambridge MA: Harvard University Press), pp. 148-155.

Quine, W.V. (1981b) “Things and Their Place in Theories” in Theories and Things (Cambridge MA: Harvard University Press), pp. 1-23.

Quine, W.V. (1951) “Two Dogmas of Empiricism” The Philosophical Review, 60, pp. 20-43. Quine, W.V. (1948) “On What There Is” Review of Metaphysics, 2, pp. 21-38.

Saatsi, Juha (2011) “The Enhanced Indispensability Argument: Representational versus Explanatory Role of Mathematics in Science" British Journal for the Philosophy of Science, 62, pp. 143-154.

Sober, Elliott (2011) “Evolution without Naturalism" in Oxford Studies in Philosophy of 
Religion Volume 3 edited by Jonathan Kvanvig (New York: Oxford University Press), pp. $187-221$.

Sober, Elliott (1993) "Mathematics and Indispensability" The Philosophical Review, 102, pp. 35-57.

Vineberg, Susan (1996) "Confirmation and the Indispensability of Mathematics to Science" Philosophy of Science, 63, Supplement, pp. S256-S263.

Yablo, Stephen (2005) "The Myth of Seven" in Fictionalism in Metaphysics edited by Mark Eli Kalderon (NY: Oxford University Press), pp. 88-115.

Yablo, Stephen (2012) “Explanation, Extrapolation, and Existence" Mind, 121, pp. 1007-1029. 